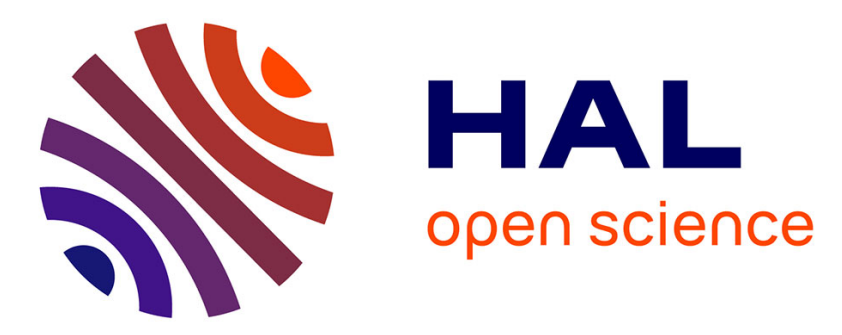

\title{
Klüver \& Bucy Syndrome: An investigation of social and affective cognition
}

Maxime Bertoux, Elisa de Paula França Resende, Leonardo Cruz de Souza

\section{To cite this version:}

Maxime Bertoux, Elisa de Paula França Resende, Leonardo Cruz de Souza. Klüver \& Bucy Syndrome: An investigation of social and affective cognition. Neurocase, In press, Epub ahead of print. inserm01848640

\section{HAL Id: inserm-01848640 https://www.hal.inserm.fr/inserm-01848640}

Submitted on 25 Jul 2018

HAL is a multi-disciplinary open access archive for the deposit and dissemination of scientific research documents, whether they are published or not. The documents may come from teaching and research institutions in France or abroad, or from public or private research centers.
L'archive ouverte pluridisciplinaire $\mathbf{H A L}$, est destinée au dépôt et à la diffusion de documents scientifiques de niveau recherche, publiés ou non, émanant des établissements d'enseignement et de recherche français ou étrangers, des laboratoires publics ou privés. 


\title{
Klüver \& Bucy Syndrome: An investigation of social and affective cognition
}

\author{
Maxime Bertoux* ${ }^{1}$, Elisa de Paula França Resende ${ }^{2} \&$ Leonardo Cruz de Souza $^{2,3}$ \\ * Corresponding author. E-mail address: maxime.bertoux@cantab.net \\ orcid.org/0000-0002-5283-503X \\ ${ }^{1}$ Memory Resources and Research Centre, Inserm U1171, Lille University Hospital, France \\ ${ }^{2}$ Programa de Pós-Graduação em Neurociências, Universidade Federal de Minas Gerais (UFMG), Belo \\ Horizonte, Minas Gerais (MG), Brazil \\ ${ }^{3}$ Departamento de Clínica Médica, Faculdade de Medicina da UFMG, Belo Horizonte, MG, Brazil.
}

\section{Acknowledgments}

We are indebted to Dr. Nathalie Guyader for the programming and interpretation of the Bubbles test and to ASP's mother. We also thank Pr. Jean Luc Truelle. MB is funded by DistALZ.

\section{Disclosure statement}

The authors report no conflicts of interest. 


\begin{abstract}
Klüver-Bucy syndrome (KBS) leads to important behavioural symptoms and social maladaptation. Rarely described in humans, no previous study has investigated the social and affective cognitive profile of KBS. Here, we report the case of ASP, a patient with history of herpetic encephalitis who developed a complete KBS at 9 years old that evolved into an incomplete KBS. Imaging examinations evidenced orbitofrontal and temporal damages. While a classic neuropsychological assessment showed a preserved global functioning, an extensive evaluation of her social and affective cognition (reversal-learning, decision-making, emotion recognition, theory of mind, creative-thinking) showed remarkable deficits. The relevancy of such findings for the characterization of cognitive damage in KBS and the field of neuropsychology are discussed.
\end{abstract}

\title{
Keywords
}

Klüver-Bucy syndrome; social cognition; decision-making; reversal learning 


\section{Introduction}

Klüver-Bucy syndrome (KBS) is a neurobehavioural syndrome that has firstly been described in rhesus monkeys after bilateral resection of anterior and medial temporal regions, including the amygdala (Hayman, Rexer, Pavol, Strite, \& Meyers, 1998; Marlowe, Mancall, \& Thomas, 1975). It has rarely been observed in humans and involves visual agnosia, hypermetamorphosis (an excessive attention to visual stimuli with a tendency to touch every perceived stimuli), oral tendency (a strong urge to bring objects to the mouth), placidity (a diminution or loss of anger and fear responses, blunted affect and obedience), hyper-sexuality and changes in dietary habits (Kluver \& Bucy, 1937). The syndrome can be either complete or incomplete and can be a chronic or a transient condition. In human, fragments of this syndrome have been observed due to a variety of different conditions such as following temporal lobes resection (Anson \& Kuhlman, 1993; Ghika-Schmid, Assal, De Tribolet, \& Regli, 1995; Obrador 1947; Terzian \& Dalle Ore, 1955), systemic lupus erythematosus (Lin, Yeh, Chen, Chang, \& Chen, 2011; Oliveira, Ferro, Foreid, Costa, \& Levy, 1989), intoxication (Sandson, Lilly, \& Sodkol, 1988), stroke (Pitt, Kriel, Wagner, \& Krach, 1995) or as a consequence of a traumatic brain injury (Asensio, 2003; Kwiatkowski, Starowicz, Milczarek, \& Kułaga, 2010; Morcos \& Guirgis, 2014; Olson, 2003; Pradhan, Singh, \& Pandey, 1998), but herpes encephalitis is considered to be the most frequently reported aetiology (Jha \& Patel, 2004).

Although most studies emphasize the cause of the syndrome and not its cognitive profile, a few previous neuropsychological observations have been made previously in adults or children (Cohen, Park, Kim, \& Pillai, 2010; De Tiège et al., 2005), including rare cases presenting a complete syndrome (e.g. Marlowe et al., 1975). These past neuropsychological observations have been important to document the general cognitive profile of KBS as well as the neural correlates of the rare symptoms composing this syndrome. However, complete neuropsychological investigations of KBS have been quite rare in the past, mainly because the syndrome is frequently associated with language impairments and could involve a lack of compliance for cognitive testing, which might stand in the way of an exhaustive cognitive assessment. Furthermore, another limit to previous investigations of 
cognition in KBS is the total absence of findings related to social and affective cognition. Social neurosciences have grown in interest and importance after the 90's and social cognition as a cognitive dimension has been quite neglected during the past decades in clinical medicine. As a growing number of psychiatric and neurologic conditions have since been found to be characterized by social cognitive dysfunctions (Kennedy \& Adolphs, 2012), social and affective cognition is now increasingly regarded as a main cognitive domain that should be evaluated in clinical setting, as suggested by the last edition of the Diagnostic and Statistical Manual of Mental Disorders (APA, 2013). Nowadays, critical functions such as theory of mind (the ability to infer what others believe, think or feel) and emotion recognition, two welldescribed processes known to carry normal social interactions, can be assessed in clinical practice with different validated tools.

The link between social behaviour, social cognition and temporal or limbic structures is also well established (Kennedy \& Adolphs, 2012). However, to our knowledge, no previous report of KBS has included social and affective cognitive assessments. The present observation intends to fill this gap in describing the nature and extend of the social cognitive and affective dysfunctions caused by polar frontotemporal damages in a patient with KBS.

\section{Case history}

We describe the case of ASP, a 35 years-old woman with a history of severe impairments in her social and affective abilities that started after an episode of herpes encephalitis in 1981, at the age of 9 years old. These difficulties were so important that she was never able to live an ordinary life, despite no major general cognitive deficits.

At 9 years old, she presented with a sudden headache, fever, vomiting, somnolence, seizures and cutaneous rash. Computed tomography head-scan showed bilateral temporal hippo-intensities. Lumbar puncture showed pleocitosis and elevated proteins in the cerebrospinal fluid (CSF). Electroencephalogram (EEG) showed bilateral temporal pseudo periodic complexes. Herpes viruses 7 and 16 were isolated from her throat, and she was treated with vidarabine for herpes encephalitis. She recovered gradually and awakened from the coma with akinetic mutism. At the 
discharge, her language was almost normal but she presented a behavioural symptomatology characterized by grasping, hyperphagia and excessive chewing.

One year after, at 10 years old, her behaviour has worsened, with hyperkinetic movements, logorrhoea, aggressiveness, agitation and childish behaviour retrieved in addition to the initial symptomatology. Her CSF and EEG were still abnormal and ASP received a second treatment with acyclovir. Afterwards, she developed hyperbulimia (she ate potatoes peelings, raw pasta, sugar cubes), hyper-sexuality (with masturbation in public) and loss of social rules (she spit on any ground frequently and used excessively obscene words frequently).

When she was 12 years old, ASP started to present behavioural stereotypies during social interactions. She was described as aggressive and also had important difficulties to maintain her attention to a particular task and a strong tendency to react to every stimulus. She had a perseverative, impulsive and exploratory behaviour. As a consequence, she ran away from her home and from the hospital many times. During these runaways, she suffered from sexual abuses. Although her behaviour deficits critically impacted her schooling and social functioning with others students, she was however able to go to an adapted school. There, she was described as being emotive but paradoxically, she couldn't express her feelings well.

During her teenage years, until 16 years old, ASP's behaviour stabilized, although it remained some aspects of what was called a "frontal syndrome", as well as occasional seizures. At this time, her cognitive profile was characterized by the presence of perseverations, stereotypies and a poor (reduced and non-spontaneous) language with maintenance difficulties in attention tests. However, her autonomy was described as being increased at this time.

At 27 years old, a standard neuropsychological assessment was described as being subnormal, with a good global efficiency as well as normal attention, praxis and memory abilities (except for spontaneous recall). Executive functioning (planning, visual conceptualisation, Luria's graphic sequence) and working memory were described as being normal as well, with the exception of verbal fluencies that were reduced, especially in its lexical (i.e. non-semantic) dimension. Similarly to all the neuropsychological examinations performed in the past, there was a clear dissociation between the observed pathological behaviour and the normal/subnormal neuropsychological performance. 
At 33 years old, ASP moved to a residency for disabled people where she shared a room with another woman. Since then, she started to have some responsibilities in the residency, such as preparing some dinners, performing grocery shopping and housework for the community. She succeeded to manage most of the aspects of her daily life but still had some restriction, such as with sugar consummation (she has a strong tendency to eat it compulsively in any form or to store it in her pockets). She took silk painting and cookery courses but failed all attempts of professional reinsertions, partially due to repeated runaway during stress situations, including from the residency.

From the acute episode of herpes encephalitis at the age of 9 and her medical and psychological state at 35 years old, the symptoms of ASP evolved. Although a "complete KBS" was retrieved during her child years, amnesia and hypersexuality disappeared over time. Placidity, dietary changes, hyperorality, visual agnosia and lack of emotional response remained the observable symptoms of what is called an “incomplete KBS".

\section{Clinical observations}

At 35 years old, ASP consulted for a neurological follow-up at the Neuropsychology Centre within the neurology department of the Pitié-Salpêtrière Hospital in Paris, France. An extensive neuropsychological assessment was performed at this time. Beside a preserved general cognitive efficiency (Mini-Mental State Exam = 29/30; Mattis Dementia Rating Scale $($ MDRS $)=121 / 144)$, cognitive functions were normal, including executive functioning and verbal episodic-like memory. In particular, programming, planning, inhibition and flexibility abilities, visual conceptual reasoning and attentional control (including sustained attention) were normal. On this domain, her cognitive performance was stable compared to the previous one performed at 27 years old (Table 1). Similarly to previous cognitive assessments, ASP still presented naming and identification difficulties for objects and famous faces (visual agnosia), as well as strongly decreased verbal fluency abilities (which explain the decreased total score of the MDRS).

(Please insert Table 1 around here) 
A social cognitive and affective assessment was also performed (Table 2). For the purpose of this study, we administered the same tests to 10 healthy controls matched on age (40 years old) and education level, except the Bubbles test and the Creative Thinking Test, for which controls data from previously published studies (Adolphs et al., 2005; de Souza et al., 2010) were considered.

The Iowa Gambling Task (Bechara, Damasio, Tranel, \& Damasio, 1997) was used to assess problem solving in the format of a decision-making task. This test is based on cards selection among 4 decks. Every deck of cards offers rewarding or punishing cards as well as, sometimes, rewarding and punishing cards (at the same time). Rewards and punishments were virtual money. As the principle of the test is not explicit and it is only told to participants that they have to maximize their gains, participants have to understand that specific decks offer a positive ratio of rewards/punishments $(\mathrm{C} \& \mathrm{D})$ although others offer the inverse ratio (A \& B). They thus have to choose adequately in order to win money. In this test, although ASP's overall ratio of choices $((\mathrm{C}+\mathrm{D})-(\mathrm{A}+\mathrm{B})=-6)$ indicates that she picked more cards in disadvantageous decks (i.e. C \& D) than in advantageous decks of cards, ASP showed a general tendency to switch from disadvantageous decks to advantageous decks over the course of the test, which is the expected normal performance. Alternative measures show that under condition of ambiguity (i.e. in the first 40 trials), ASP has a negative performance $((\mathrm{C}+\mathrm{D})-(\mathrm{A}+\mathrm{B})=-8)$ but in later trials, under known risk, she has a positive performance $((\mathrm{C}+\mathrm{D})-(\mathrm{A}+\mathrm{B})=4)$. This negative performance in the earlier trials should also be put in perspective with ASP's reversal difficulties, which was observed in the following test.

The reversal-learning paradigm involves the adaptation of behaviour to changes of stimulus-reward contingencies. Adapted from Rolls et al. (1994) paradigm, participants have to learn through successive trials to choose one stimulus appearing alone in the screen, which resulted in a gain, and to withhold the choice of a second stimulus to avoid a punishment. The two stimuli appear one by one in a random order on the screen and rewards/punishment are presented through visual and auditory feedback. A criterion of 9 correct responses within a sequence of 10 consecutive trials is needed to consider the rule as learned. Contingencies are then reversed, with the previously rewarding stimulus becoming punishing and the second one becoming rewarding. In this test, ASP failed to reverse the first learned rule, although she tried for 144 trials. 
Theory of mind (ToM) was assessed through the reduced and modified faux pas test, a part of the mini Social cognition and Emotional Assessment - mini-SEA, (Bertoux, Funkiewiez, O'Callaghan, Dubois, \& Hornberger, 2013). In this test, participants have to detect the presence of social faux pas in some stories and to provide answers to five questions assessing the understanding of the faux pas and its social consequences (Stone, Baron-Cohen, \& Knight, 1998). ASP's performance was characterized by subnormal abilities to detect social faux pas. Although she did not detect the faux pas present in some stories, she was able to explain the problematic situation and its consequences in the stories in which she identified a faux pas.

Facial emotion comparison, which involved to decide whether two emotions presented visually were similar or not, was subnormal in ASP. Facial emotion recognition, which is the second test composing the mini-SEA (Bertoux et al., 2013) involved the recognition of 35 facial emotions. Recognition abilities were impaired in ASP, particularly for fear, disgust, anger and sadness.

We decided to deepen our investigation of this emotion recognition deficit by using the "Bubbles" paradigm (Gosselin \& Schyns, 2001) to measure how ASP makes use of information from specific facial features in order to identify emotion expressions. This paradigm involves the presentation of only small regions of a randomly sampled face space expressing an emotion. Participants have then to identify the emotion presented. As the other regions of the face are scrambled, the method allows to statistically identify the extent to which specific facial features (eyes, mouth, nose regions) contribute to the recognition of the emotion. This approach was previously used in autism (Adolphs, Spezio, Parlier, \& Piven, 2008) and following amygdala damage (Adolphs et al., 2005). In ASP, this approach allowed us to identify a massive impairment of facial fear recognition and a strong reduction of the visual exploration of the eye-region of the face.

Finally, we used the Torrance Test of Creative Thinking (Torrance, 1966) to assess originality, verbal/visual fluency and flexibility in a creative context. This test showed decreased originality, fluency and flexibility for both verbal and visual modalities.

(Please insert Table 2 around here) 
Brain scintigraphy showed an absence of cerebral perfusion in the right temporal pole and bilateral orbitofrontal cortices as well as a severe hypoperfusion in medial, ventral and cingulate prefrontal cortices (Figure 1). Brain MRI showed right greater than left grey matter atrophy in the temporal lobes, especially in the right anterior temporal pole, associated with an atrophy of frontal ventral anterior regions and a sequelae cavity in the right hippocampus.

(Please insert Figure 1 around here)

\section{Discussion}

This case report is the first attempt to document and characterize the social and affective cognition in KBS. The clinical observation of ASP, a 35 years old woman with an incomplete KBS, reveals that following amygdala, temporal pole and orbitofrontal damages, the patient presented specific social and affective cognition deficits. In more details, she was unable to reverse a previously reinforced rule, suggesting adaptation difficulties in relation to stimulus-reward association changes. She was also strongly impaired in the recognition of facial emotion expressions, particularly for the recognition of fear. ASP also had difficulties in detecting social faux pas in stories depicting social interactions. Finally, she had reduced originality, fluency and flexibility in a context involving creative thinking.

Although the link between temporal or limbic cerebral lesions (causing the symptomatology of KBS) and dysfunctions of social dimension of behaviour and cognition are now well documented (Rankin et al., 2006; Rankin, Kramer, \& Miller, 2005; Davis \& Whalen, 2001), social and affective cognition has never been explored in KBS before. Considering ASP's cognitive profile, we believe that social cognition dysfunctions in KBS have been underestimated in the past and could be a core feature of KBS. The specific impairments described through the social and affective cognitive examination that we performed echoed to ASP history and daily life difficulties across her lifespan. In particular, the impossibility to reverse a previously rewarding behaviour that becomes punishing despite good conceptual, inhibition and flexibility abilities could explain real life difficulties to cope with contexts becoming problematic or negative after having been positive previously. 
In addition, ASP's severe difficulty to recognize negative facial emotions was striking. Positive emotions, such as surprise and happiness, as well as neutral expressions, were recognized within the normal range, but the patient struggled to recognize anger, disgust, sadness and fear. Therefore, we deepened the investigation of these impairments and observed a marked deficit in processing the eye regions of the face at the Bubbles test. The facial eye-region carries important information helping to identify emotion expressions such as anger or fear (Kestenbaum \& Nelson, 1992). This deficit, leading to emotion recognition difficulties, could have played a critical role in ASP social difficulties. Significant evidences of a link between amygdala and negative emotion recognition have been shown before (Davis \& Whalen, 2001), however, for ASP, whether lesions of the amygdala caused by the encephalitis are responsible for such deficits in processing the eye-region of the face remains an open question. According to Adolphs et al. (2005), the amygdala is a critical region allowing the visual system to look for and fixate the attention on other people's eyes in order to make use of such information to identify fear expression. Our results echoed those from their patient, SM, who presented this exact pattern of fear recognition deficit due to an inability to use information carried by the eye regions of the face. However, in contrary to SM, ASP was also impaired in the recognition of anger, sadness and disgust. Although amygdala lesion could be responsible for these impairments (Davis \& Whalen, 2001), difficulties in recognizing anger were also previously associated with the integrity of orbitofrontal and anterior cingulate areas and impairment in sadness recognition was related to inferior and middle temporal regions (Blair, Morris, Frith, Perrett, \& Dolan, 1999). Furthermore, disgust identification is classically associated with the anterior insula (Woolley et al., 2015). All these mentioned regions, i.e., the amygdala, orbitofrontal, inferior temporal and insula were profoundly damaged in ASP by herpes encephalitis at the age of 9 years old, which prevent any attempt to map these cognitive deficits to more specific brain lesions. In addition, although it can be assumed that she acquired the skills allowing emotion recognition before the encephalitis, given the relative consensus regarding the acquisition of such abilities at 7 years old (Durand, Gallay, Seigneuric, Robichon, \& Baudouin, 2007; Vicari, Reilly, Pasqualetti, Vizzotto, \& Caltagirone, 2000), we cannot definitely rule out the possible developmental difficulties that ASP may have had in addition to the acquired difficulties following her brain lesions. 
Indeed, past evidences also showed that facial emotion recognition skills continue to improve until the adulthood (Herba \& Phillips, 2004).

Similarly, developmental difficulties may also explain ASP's subnormal performance in the faux pas test, an assessment of theory of mind abilities that involves the understanding of social context or rules. In contrary to patients with marked difficulties to infer what other peoples think, believe or feel, ASP showed difficulties in detecting the faux pas but had no difficulties to explain them through the test when they were detected. Therefore, we concluded that her inference skills were normal, raising the possibility that other variables could have impacted her performance at this test. In particular, we believe that social norms processing may be disturbed in ASP. Amygdala, temporal lobe, insula and medial prefrontal cortex are assumed to be critical for social norms acquisition and enforcement (Buckholtz \& Marois, 2012; Gu et al., 2015). These neural dysfunctions could explain ASP difficulties to detect the faux pas, which could be considered as social norms violation. In addition, considering that the herpes encephalitis occurred at an early age in ASP, where a child is able to respond to third-party norm violations (Vaish, Missana, \& Tomasello, 2011) but is still in the process of integrating social norms and automatisms (Blackmore, 2008), we think this developmental disruption could have impacted ASP ability to analyse and explain social faux pas and to adapt herself to complex social contexts, despite good mentalizing abilities.

We also found that ASP had impaired creative thinking, in both visual and verbal domains. This impairment was evidenced by the TTCT, which was designed to assess the key dimensions of creativity. This test has been employed in both clinical and research contexts and provides scores of fluency (the number of productions), flexibility (the ability to provide different categories of productions), originality (the ability to create rare productions) and elaboration (the ability to enrich productions with details); all these creative domains being affected in ASP. It has been demonstrated that brain diseases can impair creative production (Schott, 2012; de Souza et al, 2014). More specifically, reduced creative performance has been related to prefrontal damages (de Souza et al, 2010). From a cognitive point of view, creativity may be defined as "the ability to produce work that is both original (new, unusual, unexpected) and valuable (useful, adaptive, appropriate)" (Dietrich, 2004; Sternberg, 1999). In line with this definition, it is considered that creative thinking relies on different cognitive abilities, such as flexibility, abstract thinking, planning 
and attention (de Souza et al, 2010; Gonen-Yaacovi et al, 2013). Besides these "classical" functions, it is highly probable that affective cognition plays an important role in creative thinking and production. Amygdala and orbitofrontal cortex in particular have been pointed out as key structures carrying the emotional and motivational dimension of creativity. In addition, the medial prefrontal cortex and temporal pole, key regions in theory of mind processing, have also been shown to be involved in the creative-ideation processes of creativity (Bashwiner et al., 2016). The present report reinforces the concept of creativity as a complex and sophisticated set of multidomains neurocognitive abilities, depending on the integrity of prefrontal and temporal regions and requiring the efficient integration of different cognitive representations, including affective ones.

Finally, this case report also highlights two important dissociations that are relevant for clinicians and the field of neuropsychology. First is the dissociation between ASP's daily life difficulties and her normal/subnormal "classic" neuropsychological profile (with the exception of visual agnosia). Indeed, despite the close support of her family, ASP's life was and is still marked by difficulties to adapt herself to her social environment. However, these important social adaptation difficulties - strongly impacting her daily activities - were not reflected at all in her standard neuropsychological assessment. For example, given ASP history, one could have expected inhibition impairment and major executive dysfunctions, but her profile to all executive measures was normal. The second dissociation that should be highlighted is between the classic neuropsychological performance and the social and affective cognitive scores. ASP indeed presented a clear dissociation between preserved executive, memory or attention functioning and impaired social and affective cognition. Taken together, these dissociations point out to an independence between the social dimensions of behaviour/cognition and the more "classic" neuropsychological assessment.

Social interactions being critical in almost every aspects of Human life, these two dissociations cast doubt about the ecological validity of the classic neuropsychological assessment. Indeed, most of our daily life activities are motivated and/or modulated by social goals and contexts, however, our current conception of mental functioning assessment historically exclude its social and affective dimensions, although it could be considered as the most important one. On the one 
hand, the current neuropsychological assessment does not allow evaluating to what extend a cognitive dysfunction impacts the social and affective life; and on the other hand, it generally does now allow to assess whether the more specifically social processes are preserved or not.

Based on this observation, together with others from different conditions (e.g. Bertoux et al., 2016), we believe there is a need for new, ecologically relevant neuropsychological tools that could integrate the missing social dimension in the assessment of cognitive functions such as memory, decision-making, etc., in order to improve the ecological validity of the available clinical tools. These new tools should overcome the limitations of currently available social-cognitive tests. They should less rely on language or executive functions, provide purest measure of specific processes and be highly sensitive but also specific to their dysfunctions. In addition, they should present good psychometric values of validity and reliability, which are not always available for tests issued from experimental studies. This case also highlights the need to cast light on social norms acquisition and identification processes as currently, no test exists to assess this dimension of social cognition.

In addition, this dissociation between social cognition and more classical cognitive functions suggest that KBS could represent an efficient prototype to study the processes allowing social adaptation, similarly to behavioural variant frontotemporal dementia (bvFTD). However, a limit to such approach is that group studies on KBS would be difficult to conduct due to the rarity of the syndrome. This is why we consider that the case of ASP has both clinical and theoretical relevancy to the field, although we acknowledge that this single case approach implies some methodological limitations that cannot be overcomed. In this report, limitations mostly concern the variation of some neuropsychological scores between the two last assessments, for which we cannot provide any definitive interpretation, as well as the inclusion of a small $(<15)$ sample of control participants, which could have hindered our interpretations.

Taken together, this first observation of social cognition in KBS shows that this syndrome can manifest as a social and affective cognitive disorder, which critically impact behaviour in turn. Whether complete or incomplete KBS could similarly impact social cognition remains a question that need to be answered by 
future studies. This report also provides critical input on the role of polar temporal, orbitofrontal and amygdala in social behaviour and adaptation. Finally, it does show that currently, the neuropsychological tools that are classically used for clinical examinations in neurology and psychiatry does not capture the social and affective dimensions of cognition and behaviour. New tests are then strongly needed to affine our measure of social cognition, as well as to transform the current neuropsychological assessment into a more ecological evaluation, closer to daily life activities and difficulties. 
Standard Cognitive Tests

\begin{tabular}{lcc}
\hline Mini Mental State Examination & $30 / 30$ & $29 / 30$ \\
\hline Frontal score & $54 / 60^{*}$ & $52 / 60^{*}$ \\
\hline Wisconsin Card Sorting Task Revised & $20 / 20$ & $20 / 20$ \\
\hline Criteria & 6 & 6 \\
\hline Errors & 2 & 0 \\
\hline Perseverations & 1 & $3 / 10^{*}$ \\
\hline Verbal Fluency & $3 / 10^{*}$ & 2 \\
\hline Lexical fluency (1min) & 10 & 5 \\
\hline Semantic fluency (1min) & $10 / 10$ & $10 / 10$ \\
\hline Graphic Sequences & $20 / 20$ & $19 / 20$ \\
\hline Environmental dependency assessment & $9 / 19$ & $9 / 19$ \\
\hline Verbal Similarities (WAIS) & 32 & 32 \\
\hline Tower of London & 10 & 10 \\
\hline Time score & 32 & \\
\hline Score & 32 & \\
\hline
\end{tabular}

\section{Free and Cued Selective Reminding Test}

\begin{tabular}{lll}
\hline Encoding & $16 / 16$ & $16 / 16$ \\
\hline Free recall & $20 / 48$ & $32 / 48$ \\
\hline Total recall & $48 / 48$ & $48 / 48$ \\
\hline Delayed total recall & $16 / 16$ & $16 / 16$ \\
\hline Rey complex figure & & \\
\hline Rey complex figure copy & $36 / 36$ & $36 / 36$ \\
\hline Rey complex figure 3m recall & $22 / 36$ & $15 / 36$ \\
\hline Picture identification & N.A. & $28 / 35^{*}$ \\
\hline Picture naming & N.A. & $24 / 35^{*}$ \\
\hline Famous faces & & $8 / 35^{*}$ \\
\hline Identification & N.A. & $7 / 35^{*}$ \\
\hline Naming & N.A. & $32 / 35$ \\
\hline Knowledge & N.A. & \\
\hline
\end{tabular}

Table 1 - ASP's profile of performance on standard cognitive assessment at 27 and 35 years old. * indicates a decrease compared to normative data for her age and education level. N.A. : Non available 


\begin{tabular}{|c|c|c|}
\hline Social \& affective cognitive assessment & ASP & Controls \\
\hline Mini-SEA (composite score) (/30) & 18.2 & $26.7(1.9)$ \\
\hline Theory of mind (/15) & 11.3 & $14.3(0.9)$ \\
\hline Emotion recognition $(/ 15)$ & 6.9 & $12.4(1.4)$ \\
\hline Total recognition (\% of accuracy) & $46 \%$ & $82.5 \%(9.1)$ \\
\hline Happiness & $80 \%$ & $97.8 \%(6.7)$ \\
\hline Fear & $0 \%$ & $60 \%(26.5)$ \\
\hline Disgust & $20 \%$ & $86.7 \%(14.1)$ \\
\hline Neutral & $80 \%$ & $97.8 \%(6.7)$ \\
\hline Surprise & $100 \%$ & $91.1 \%(14.6)$ \\
\hline Anger & $40 \%$ & $75.6 \%(19.4)$ \\
\hline Sadness & $0 \%$ & $68.9 \%(26.7)$ \\
\hline Facial emotion comparison (total) (\% of accuracy) & $71 \%$ & $84.1 \%(4.4)$ \\
\hline Bubbles test (total) (\% of accuracy)* & $44.15 \%$ & $89.7 \%$ (N.A.) \\
\hline Happiness & $85 \%$ & $100 \%$ (N.A.) \\
\hline Fear & $1.6 \%$ & $84 \%$ (N.A.) \\
\hline Disgust & $20 \%$ & $76 \%$ (N.A.) \\
\hline Surprise & $78.3 \%$ & $96 \%$ (N.A.) \\
\hline Anger & $15 \%$ & $82 \%$ (N.A.) \\
\hline Sadness & $65 \%$ & $100 \%$ (N.A.) \\
\hline \multicolumn{3}{|l|}{ Reversal Learning } \\
\hline Number of reversal & 0 & $2.7(0.7)$ \\
\hline Number of trial before reversing the $1^{\text {st }}$ rule & I & $10.8(1.9)$ \\
\hline \multicolumn{3}{|l|}{ Iowa Gambling Task } \\
\hline Total $(\mathrm{A}+\mathrm{B})-(\mathrm{C}+\mathrm{D})$ & 2 & $3(21.0)$ \\
\hline Cards $1-20$ & -6 & $-4(4.3)$ \\
\hline Cards 21-40 & -4 & $-2(3.7)$ \\
\hline Cards 41-60 & 2 & $1(10.0)$ \\
\hline Cards 61-80 & -4 & $5(8.1)$ \\
\hline Cards $81-100$ & 6 & $3(10.1)$ \\
\hline \multicolumn{3}{|l|}{ Creativity thinking (Torrance test) $* *$} \\
\hline Verbal fluency & 3 & $60.6( \pm 22.7)$ \\
\hline Verbal flexibility & 3 & $31.4( \pm 7)$ \\
\hline Verbal originality & 1 & $38( \pm 16.4)$ \\
\hline Visual fluency & 2 & $21.5( \pm 5.7)$ \\
\hline Visual originality & 1 & $14.9( \pm 4.8)$ \\
\hline
\end{tabular}

Table 2 - ASP's profile of performance on social and affective cognitive assessment and controls' mean and (SD). * Norms of control women of comparable age (37.5 years old) from Adolphs et al., 2005. ** Norms from de Souza et al., 2010. N.A. : Non available, see Adolphs et al., 2005. 
Figure 1 Title and legend

Figure 1 - Brain scintigraphy (single-photon emission computed tomography) of ASP showing remarkable hypoperfusion in the temporal regions, with no flux detected in the right anterior temporal lobe and orbitrofrontal cortex. From top to bottom: coronal, sagittal and transverse planes.

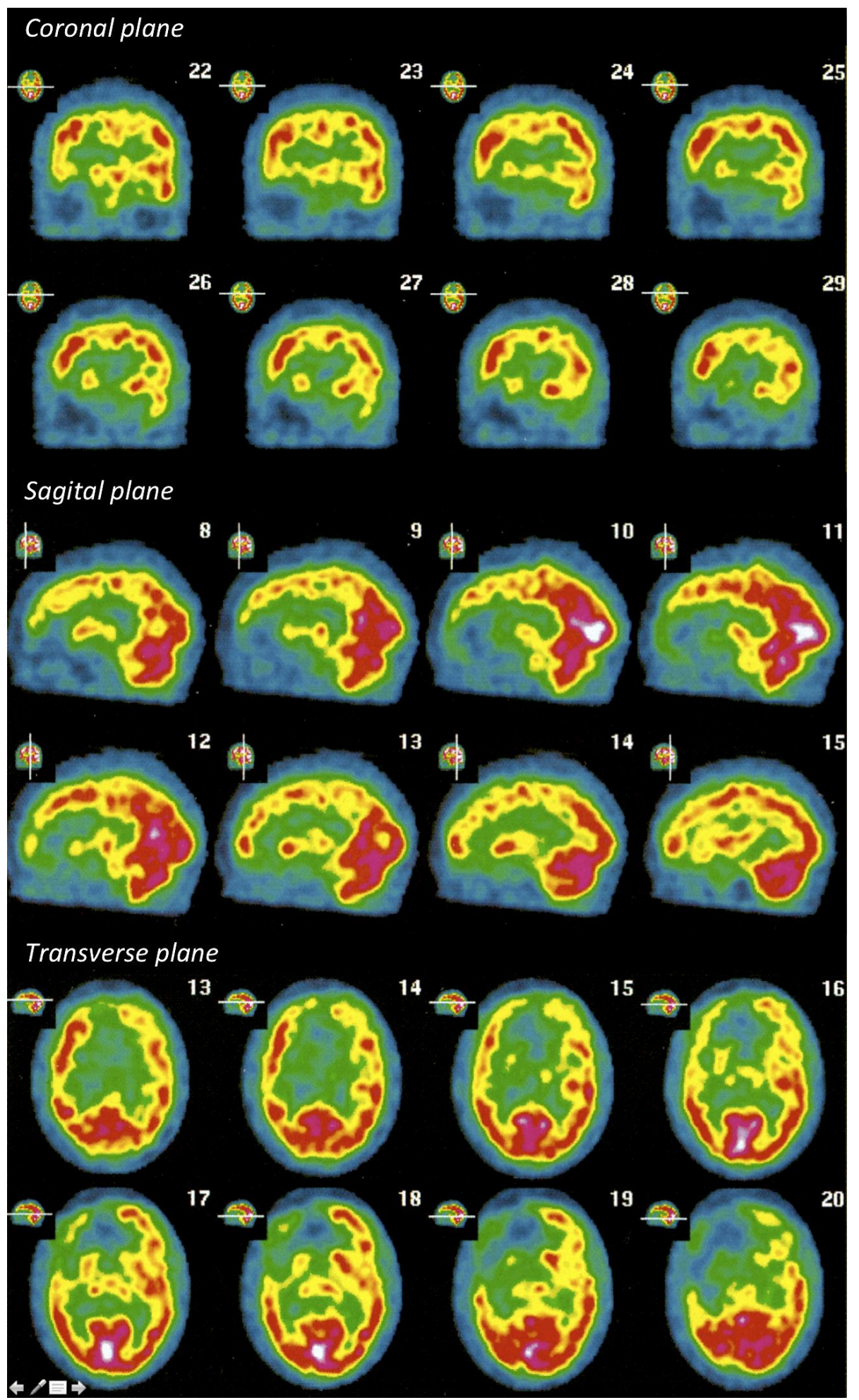




\section{References}

Adolphs, R., Gosselin, F., Buchanan, T. W., Tranel, D., Schyns, P., \& Damasio, A. R. (2005). A mechanism for impaired fear recognition after amygdala damage. Nature, 433(7021), 68-72. doi: 10.1038/nature03086

Adolphs, R., Spezio, M. L., Parlier, M., \& Piven, J. (2008). Distinct face-processing strategies in parents of autistic children. Curr Biol, 18(14), 1090-1093. doi: 10.1016/j.cub.2008.06.073

Anson, J. A., \& Kuhlman, D. T. (1993). Post-ictal Klüver-Bucy syndrome after temporal lobectomy. J Neurol Neurosurg Psychiatry, 56(3), 311-313.

APA. (2013). American Psychiatric Association . Diagnostic and statistical manual of mental disorders. (5th ed.). Arlington, VA: American Psychiatric Publishing.

Asensio, J. A. (2003). Klüver-Bucy syndrome as a result of minor head trauma. South Med J, 96(7), 726. doi: 10.1097/01.SMJ.0000078644.46905.C3

Bechara, A., Damasio, H., Tranel, D., \& Damasio, A. R. (1997). Deciding advantageously before knowing the advantageous strategy. Science, 275(5304), 1293-1295.

Bertoux, M., O'Callaghan, C., Dubois, B., Hornberger, M. (2016). In two minds: executive functioning versus theory of mind in behavioural variant frontotemporal dementia. J Neurol Neurosurg Psychiatry, 87(3):231-4.

Bertoux, M., Funkiewiez, A., O'Callaghan, C., Dubois, B., \& Hornberger, M. (2013). Sensitivity and specificity of ventromedial prefrontal cortex tests in behavioral variant frontotemporal dementia. Alzheimers Dement, $9(5$ Suppl), S84-94. doi: 10.1016/j.jalz.2012.09.010

Baschwiner, D.M., Wertz, C.J., Flores, R.A., Jung, R.E. (2016). Musical creativity "revealed" in brain structure: interplay between motor, default mode, and limbic networks. Sci Rep, 18;6:20482.

Blackmore, S.J. (2008). The social brain in adolescence. Nature Reviews Neuroscience 9, 267-277.

Blair, R. J., Morris, J. S., Frith, C. D., Perrett, D. I., \& Dolan, R. J. (1999). Dissociable neural responses to facial expressions of sadness and anger. Brain, 122 ( Pt 5), 883-893.

Buckholtz, J. W., \& Marois, R. (2012). The roots of modern justice: cognitive and neural foundations of social norms and their enforcement. Nat Neurosci, 15(5), 655-661. doi: 10.1038/nn.3087

Cohen, M. J., Park, Y. D., Kim, H., \& Pillai, J. J. (2010). Long-term neuropsychological follow-up of a child with Klüver-Bucy syndrome. Epilepsy Behav, 19(4), 643-646. doi: 10.1016/j.yebeh.2010.09.003

Davis, M., Whalen, P.J. (2001). The amygdala: vigilence and emotion. Molecular Psychiatry, 6, 13-34.

De Souza, L.C., Volle, E., Bertoux, M., Czernecki, V., Funkiewiez, A., Allali, G., Leroy, B., Sarazin, M., Habert, M-O., Dubois, B., Kas, A., Levy, R. (2010). Poor creativity in frontotemporal dementia: A window into the neural bases of the creative mind. Neuropsychologia, 48(13):3733-42.

De Souza, L.C., Guimarães, H.C., Teixeira, A.L., Caramelli, P., Levy, R., Dubois, B., Volle, E., (2014). Frontal lobe neurology and the creative mind. Front Psychol, 23;5:761.

De Tiège, X., De Laet, C., Mazoin, N., Christophe, C., Mewasingh, L. D., Wetzburger, C., \& Dan, B. (2005). Postinfectious immune-mediated encephalitis after 
pediatric herpes simplex encephalitis. Brain Dev, 27(4), 304-307. doi: 10.1016/j.braindev.2004.07.007

Dietrich, A. (2004). The cognitive neuroscience of creativity. Psychon Bull Rev, 11(6), 1011-1026.

Durand, K., Gallay, M., Seigneuric, A., Robichon, F., \& Baudouin, J. Y. (2007). The development of facial emotion recognition: the role of configural information. J Exp Child Psychol, 97(1), 14-27. doi: 10.1016/j.jecp.2006.12.001

Ghika-Schmid, F., Assal, G., De Tribolet, N., \& Regli, F. (1995). Klüver-Bucy syndrome after left anterior temporal resection. Neuropsychologia, 33(1), 101- 113.

Gonen-Yaacovi, G., de Souza, L.C., Levy, R., Urbanski, M., Josse, G., Volle, E., (2013). Rostral and caudal prefrontal contribution to creativity: a meta-analysis of functional imaging data. Front Hum Neurosci, 14;7:465.

Gosselin, F., \& Schyns, P. G. (2001). Bubbles: a technique to reveal the use of information in recognition tasks. Vision Res, 41(17), 2261-2271.

Gu, X., Wang, X., Hula, A., Wang, S., Xu, S., Lohrenz, T. M., . . Montague, P. R. (2015). Necessary, yet dissociable contributions of the insular and ventromedial prefrontal cortices to norm adaptation: computational and lesion evidence in humans. J Neurosci, 35(2), 467-473. doi: 10.1523/JNEUROSCI.2906-14.2015

Hayman, L. A., Rexer, J. L., Pavol, M. A., Strite, D., \& Meyers, C. A. (1998). KlüverBucy syndrome after bilateral selective damage of amygdala and its cortical connections. J Neuropsychiatry Clin Neurosci, 10(3), 354-358. doi: 10.1176/jnp.10.3.354

Herba, C., \& Phillips, M. (2004). Annotation: Development of facial expression recognition from childhood to adolescence: behavioural and neurological perspectives. J Child Psychol Psychiatry, 45(7), 1185-1198. doi: 10.1111/j.1469-7610.2004.00316.x

Jha, S., \& Patel, R. (2004). Kluver- Bucy syndrome - An experience with six cases. Neurol India, 52, 369-371.

Kennedy, D. P., \& Adolphs, R. (2012). The social brain in psychiatric and neurological disorders. Trends Cogn Sci, 16(11), 559-572. doi: 10.1016/j.tics.2012.09.006

Kestenbaum, R., \& Nelson, C. A. (1992). Neural and behavioral correlates of emotion recognition in children and adults. J Exp Child Psychol, 54(1), 118.

Kluver, H., \& Bucy, P. (1937). Psychic blindness and other symptoms following bilateral temporal lobectomy in rhesus monkeys. Am J Physiol, 119, 352353.

Kwiatkowski, S., Starowicz, A., Milczarek, O., \& Kułaga, A. (2010). [Postraumatic klüver-Bucy syndrome--description and comparison of two clinical cases]. Psychiatr Pol, 44(3), 371-380.

Lin, H. F., Yeh, Y. C., Chen, C. F., Chang, W. C., \& Chen, C. S. (2011). Kluver-Bucy syndrome in one case with systemic lupus erythematosus. Kaohsiung J Med Sci, 27(4), 159-162. doi: 10.1016/j.kjms.2010.12.011

Marlowe, W., Mancall, E., \& Thomas, J. (1975). Complete Klüver-Bucy syndrome in man. Cortex, 1, 53-59. 
Morcos, N., \& Guirgis, H. (2014). A case of acute-onset partial Kluver-Bucy syndrome in a patient with a history of traumatic brain injury. $J$ Neuropsychiatry Clin Neurosci, 26(3), E10-11. doi: 10.1176/appi.neuropsych.13060132

Obrador, S. (1947). Temporal lobotomy. Journal of Neuropathology and Experimental Neurology, 6(2), 185 -193.

Oliveira, V., Ferro, J. M., Foreid, J. P., Costa, T., \& Levy, A. (1989). Kluver-Bucy syndrome in systemic lupus erythematosus. J Neurol, 236(1), 55-56.

Olson, D. A. (2003). Klüver-Bucy syndrome as a result of minor head trauma. South Med J, 96(3), 323. doi: 10.1097/01.SMJ.0000078644.46905.C3

Pitt, D. C., Kriel, R. L., Wagner, N. C., \& Krach, L. E. (1995). Kluver-Bucy syndrome following heat stroke in a 12-year-old girl. Pediatr Neurol, 13(1), 73-76.

Pradhan, S., Singh, M. N., \& Pandey, N. (1998). Kluver Bucy syndrome in young children. Clin Neurol Neurosurg, 100(4), 254-258.

Rankin, K. P., Gorno-Tempini, M. L., Allison, S. C., Stanley, C. M., Glenn, S., Weiner, M. W., \& Miller, B. L. (2006). Structural anatomy of empathy in neurodegenerative disease. Brain, 129(Pt 11), 2945-2956. doi: 10.1093/brain/awl254

Rankin, K. P., Kramer, J. H., \& Miller, B. L. (2005). Patterns of cognitive and emotional empathy in frontotemporal lobar degeneration. Cogn Behav Neurol, 18(1), 28-36.

Rolls, E. T., Hornak, J., Wade, D., \& McGrath, J. (1994). Emotion-related learning in patients with social and emotional changes associated with frontal lobe damage. J Neurol Neurosurg Psychiatry, 57(12), 1518-1524.

Sandson, T. A., Lilly, R. B., \& Sodkol, M. (1988). Kluver-Bucy syndrome associated with delayed post-anoxic leucoencephalopathy following carbon monoxide poisoning. J Neurol Neurosurg Psychiatry, 51(1), 156-157.

Schott, G.D., (2012). Pictures as a neurological tool: lessons from enhanced and emergent artistry in brain disease. Brain, 135(6):1947-63.

Sternberg, R. J. L., (1999). The concept of creativity: Prospects and paradigms. . In R. J. Sternberg (Ed.), Handbook of creativity (pp. 137-152). Cambridge: Cambridge University Press.

Stone, V. E., Baron-Cohen, S., \& Knight, R. T. (1998). Frontal lobe contributions to theory of mind. J Cogn Neurosci, 10(5), 640-656.

Terzian, H., \& Dalle Ore, G. (1955). Syndrome of Klüver and Bucy Reproduced in Man by Bilateral Removal of Temporal Lobes. Neurology, 5, 373-380.

Torrance, E. P. (1966). Torrance Tests of Creative Thinking. Princeton, N.J.: Personnel Press.

Vaish, A., Missana, M., \& Tomasello, M. (2011). Three-year-old children intervene in third-party moral transgressions. Br J Dev Psychol, 29(Pt 1), 124-130. doi: 10.1348/026151010X532888

Vicari, S., Reilly, J. S., Pasqualetti, P., Vizzotto, A., \& Caltagirone, C. (2000). Recognition of facial expressions of emotions in school-age children: the intersection of perceptual and semantic categories. Acta Paediatr, 89(7), 836-845.

Woolley, J. D., Strobl, E. V., Sturm, V. E., Shany-Ur, T., Poorzand, P., Grossman, S., . . . Rankin, K. P. (2015). Impaired Recognition and Regulation of Disgust Is Associated with Distinct but Partially Overlapping Patterns of Decreased 
Gray Matter Volume in the Ventroanterior Insula. Biol Psychiatry, 78(7), 505-514. doi: 10.1016/j.biopsych.2014.12.031 